\title{
Macrolide-Resistant Mycoplasma genitalium in Southeastern Region of the Netherlands, 2014-2017
}

\author{
Liesbeth Martens, Sharon Kuster, Wilco de Vos, Maikel Kersten, Hanneke Berkhout, Ferry Hagen
}

Mycoplasma genitalium infections of the urogenital tract are usually treated with azithromycin; however, for the past several years, rates of azithromycin treatment failure have increased. To document the occurrence and frequency of macrolide resistance-mediating mutations (MRMMs) in M. genitalium infections, we collected 894 M. genitaliumpositive samples during April 2014-December 2017 and retrospectively tested them for MRMMs. We designated 67 samples collected within 6 weeks after a positive result as test-of-cure samples; of these, 60 were MRMM positive. Among the remaining 827 samples, the rate of MRMM positivity rose from $22.7 \%$ in 2014 and $22.3 \%$ in 2015 to $44.4 \%$ in 2016 but decreased to $39.7 \%$ in 2017 . Because of these high rates of MRMMs in $M$. genitalium infections, we recommend that clinicians perform tests of cure after treatment and that researchers further explore the clinical consequences of this infection.

Nince Mycoplasma genitalium was first isolated from $\checkmark$ men with nongonococcal urethritis in 1981, this bacterium has been recognized as a possible pathogen of the genitourinary tract (1). During the first decade after its discovery, its fastidious nature and slow growth rate complicated research into its clinical significance. Its association with nongonococcal urethritis in men was not established until the mid-1990s $(2,3)$, when molecular testing in research settings had become available. Now M. genitalium is widely recognized as a frequent cause of male urethritis $(4,5)$, a likely cause of cervicitis and pelvic inflammatory disease in women $(6)$, and a possible cause of several other genitourinary syndromes (4-7).

The commonly used treatment for $M$. genitalium infections is azithromycin, either in a single dose of $1,000 \mathrm{mg}$ or as a 5-day regimen (500 $\mathrm{mg}$ on the first day, followed by $250 \mathrm{mg}$ on the subsequent 4 days). During the past decade,

Author affiliations: Radboud University Medical Center, Nijmegen, the Netherlands (L. Martens); Canisius-Wilhelmina Hospital, Nijmegen (L. Martens, S. Kuster, W. de Vos, M. Kersten, H. Berkhout, F. Hagen); Westerdijk Fungal Biodiversity Institute, Utrecht, the Netherlands (F. Hagen)

DOI: https://doi.org/10.3201/eid2507.181556 azithromycin treatment failure has been reported with increasing frequency $(8)$. Clinical cure rates reported before 2008 were generally $>80 \%(9-11)$ but more recently have dropped to as low as $54 \%(12,13)$. A single dose of azithromycin is the preferred treatment for nongonococcal urethritis in many countries, including Australia (14), the Netherlands (15), the United States (10), and the United Kingdom (17). Moreover, Chlamydia trachomatis infections are also commonly treated with a single dose of azithromycin, often without excluding co-infection with M. genitalium (1417). However, it has been suggested that the single-dose regimen of azithromycin is actually facilitating the development of macrolide resistance $(18,19)$.

In the Netherlands, routine testing for $M$. genitalium is not included in national sexually transmitted disease (STD) screening protocols $(15,20,21)$. In a recent revision of the national protocol, screening for $M$. genitalium infections in men with nongonococcal urethritis is mentioned but not explicitly advised (22). The protocol states that the treatment of choice for symptomatic men and their partners is azithromycin for 5 days or moxifloxacin for 7-10 days. Follow-up is not mentioned (22). Most local hospital-based guidelines advise azithromycin in a 5-day regimen only; some advise a test of cure. Detection of macrolide resistance--mediating mutations (MRMMs) has, so far, not been included as part of the diagnostic work-up.

To document the occurrence and frequency of MRMMs, we conducted a retrospective study in the Netherlands during April 2014-December 2017. We tested samples that were positive for $M$. genitalium during the study period for MRMMs by using a molecular diagnostic approach.

\section{Material and Methods}

\section{Sampling}

The Laboratory of Medical Microbiology of the CanisiusWilhelmina Hospital in Nijmegen, the Netherlands, is the primary diagnostic laboratory for the hospital itself, other care institutions, and general practitioners in the area. All samples referred to this laboratory for STD diagnostics 
starting in April 2014 were tested for M. genitalium, and samples that were positive were stored at $-80^{\circ} \mathrm{C}$. The study was approved by the Canisius-Wilhelmina Hospital Institution Review Board. Because patient identities were anonymous, written informed consent of participants was not required.

\section{DNA Extraction}

We collected $M$. genitalium-positive samples (determined by routine diagnostic in-house quantitative PCR [qPCR]) from the $-80^{\circ} \mathrm{C}$ storage. After thawing the samples, we homogenized them by short vortexing and subsequently mixed a $200-\mu \mathrm{L}$ sample with $20 \mu \mathrm{L}$ internal control (phocine herpes virus [PhHV]) into a 96-deep well plate and extracted nucleic acids by using the MagNA Pure 96 automatic platform (Roche, http://www.roche.com). Nucleic acids eluates were directly subjected to molecular testing and stored at $-20^{\circ} \mathrm{C}$ until further use.

\section{Detection of STDs}

We again subjected all samples to the same routine diagnostic in-house qPCR that simultaneously detects Trichomonas vaginalis, $M$. genitalium, and the internal extraction and amplification control PhHV. The qPCR mixture consisted of $2 \mu \mathrm{L}$ primers and probes MgeFwd (5'-GAGAAATACCTTGATGGTCAGCAA-3', $5 \mathrm{pmol} /$ $\mu \mathrm{L}$ ), MgeRvd (5'-GTTAATATCATATAAAGCTCTACCGTTGTTATC-3', $5 \mathrm{pmol} / \mu \mathrm{L})$, MgeProbe (5'-FAMACTTTGCAATCAGAAGGT-MGB-3', $2 \mathrm{pmol} / \mu \mathrm{L})$, TvaFwd (5'-CCTCAGTTCGCAAAGGC-3', $5 \mathrm{pmol} / \mu \mathrm{L}$ ), TvaRvd (5'-TTCAGCGACCATTCCCA-3', $5 \mathrm{pmol} / \mu \mathrm{L})$, TvaProbe (5'-HEX-CATTGACGCACTCATGACGAACGA-BHQ1-3', 2 pmol/ $\mu \mathrm{L}$ ), PhHVFwd (5'-GGGCGAATCACAGATTGAATC-3', $5 \mathrm{pmol} / \mu \mathrm{L})$, PhHVRvd (5'-GCGGTTCCAAACGTACCAA- $3^{\prime}, 5 \mathrm{pmol} / \mu \mathrm{L}$ ), and PhHVProbe (5'-Cy5-TTTTTATGTGTCCGCCACCATCTGGATCBHQ2-3', 2 pmol/ $\mu \mathrm{L})(23) ; 10 \mu \mathrm{L} 2 \times$ Fast Advanced Master Mix (Applied Biosystems, https://www.thermofisher.com); and $8 \mu \mathrm{L}$ DNA sample. The qPCR reaction was conducted in a LightCycler 480-II (Roche Diagnostics) with the following protocol: UNG (uracil- $N$-glycosylase) treatment for $2 \mathrm{~min}$ at $50^{\circ} \mathrm{C}, 10 \mathrm{~min}$ polymerase activation at $96^{\circ} \mathrm{C}, 45$ cycles of denaturation for $5 \mathrm{~s}$ at $96^{\circ} \mathrm{C}$ and $12 \mathrm{~s}$ at $60^{\circ} \mathrm{C}$ (fluorescence measurement), and a final cooling step for $30 \mathrm{~s}$ at $40^{\circ} \mathrm{C}$. We included a negative extraction control, a negative template control, and a positive template control.

\section{Detection of $\boldsymbol{M}$. genitalium and MRMMs}

The TVMGres qPCR assay developed by NYtor (https:// www.nytor) is a multiplex qPCR assay that detects $T$. vaginalis and M. genitalium and includes the internal control $\mathrm{PhHV}$. The assay simultaneously detects the single-nucleotide polymorphisms A2058C, A2058G, A2058T, and
A2059G in the 23S ribosomal RNA-encoding region of $M$. genitalium, which together account for $>95 \%$ of the cases of azithromycin resistance (24). We added $5 \mu \mathrm{L}$ of the nucleic acids extract to $15-\mu \mathrm{L}$ reaction mix that contained qPCR master mix and the primer/probe mix from the TVMGres qPCR assay. We performed the qPCR reactions on a LightCycler 480-II instrument (Roche Diagnostics) using a reaction protocol consisting of a polymerase activation step of $3 \mathrm{~min}$ at $95^{\circ} \mathrm{C}$, followed by 45 cycles of $15 \mathrm{~s}$ at $95^{\circ} \mathrm{C}$ and 1 min at $60^{\circ} \mathrm{C}$. Detection was done by measuring the fluorescence signals of FAM (for $T$. vaginalis), CAL Fluor Orange 560 (for M. genitalium mutations), CAL Fluor Red 610 (for M. genitalium detection), and TYE665 (for internal control) (https://eu.idtdna.com for all dyes). We considered a sample to be valid if an amplification curve for any of the pathogen targets or the internal control was present.

We defined wild-type $M$. genitalium as that in a sample that was positive for M. genitalium without the presence of a positive MRMM signal. We defined resistant $M$. genitalium as that in a sample positive for both $M$. genitalium and MRMMs.

\section{Statistical Analyses}

We collected data in Microsoft Excel (Microsoft, https://www.microsoft.com) and used Microsoft Office Excel and SPSS (IBM, https://www.ibm.com) for analysis. We calculated $p$ values in SPSS by using the $\chi^{2}$ test and 2-sample $t$-test.

\section{Results}

We tested 28,408 samples from 20,537 patients for the presence of STD organisms. Most $(\mathrm{n}=25,132 ; 88.5 \%)$ samples were provided by general practitioners, $3,087(10.9 \%)$ by hospitals, and $189(0.7 \%)$ from other and unknown locations. M. genitalium was detected in 1,146 (4.0\%) samples from 879 patients $(4.3 \%)$. For 7 patients, multiple samples that were collected on the same day were positive; for each of these patients, we included only 1 of these samples, which left 1,139 samples, 936 of which were available for further testing. The remaining 203 samples were either not stored or were of inadequate volume for further analysis. We found no statistically significant differences between available and unavailable samples (Table).

A total of 23 samples were negative for $M$. genitalium by the routine diagnostic in-house qPCR and the TVMGres qPCR assay. We excluded these samples from our study, together with 18 samples repeatedly showing incongruous results (i.e., in-house qPCR result not matching the TVMGres qPCR result). We also excluded another sample that repeatedly had an inhibited internal control in the TVMGres qPCR assay because of a concurrent $T$. vaginalis infection. We provide an overview of all included and excluded samples (Figure 1). 
Table. Characteristics of samples available and unavailable for further testing in study of macrolide-resistant Mycoplasma genitalium in southeastern region of the Netherlands, 2014-2017*

\begin{tabular}{|c|c|c|c|}
\hline Characteristic & Available samples, $\%(n=936)$ & Unavailable samples, \% $(n=203)$ & $p$ value \\
\hline \multicolumn{4}{|l|}{ Patient sex } \\
\hline $\mathrm{F}$ & 67.3 & 69.5 & 0.546 \\
\hline M & 32.7 & 30.5 & \\
\hline Proportion sent in by general practitioner & 92.2 & 90.2 & 0.343 \\
\hline Proportion test of cure & 7.3 & 8.9 & 0.357 \\
\hline
\end{tabular}

\section{Characteristics of the Study Population}

Of the 28,408 samples that were tested for M. genitalium during the study period, 19,393 (68.3\%) originated from female patients and 9,015 (31.7\%) from male patients $(2.2: 1$ ratio). The percentages of $M$. genitalium positivity were similar for male (4.1\%) and female (4.0\%) patients.

Average age at the time of testing was 32.0 years; female patients (average 31.3 years of age) were younger than male patients (average 33.6 years of age). The average age of M. genitalium-positive male patients (33.1 years) was slightly lower than that of $M$. genitalium-negative male patients (33.6 years; $\mathrm{p}=0.36$ ). M. genitalium-positive female patients were 2.8 years younger than $M$. genitalium-negative female patients ( 28.5 vs. 31.3 years; $\mathrm{p}<0.001$ ).

\section{Epidemiology}

A total of 894 samples had positive results for M. genitalium when tested by the routine diagnostic in-house qPCR and by the TVMGres qPCR assay. Of these, 67 (7.5\%) samples were collected within 6 weeks of a previous positive M. genitalium result. These retests were considered positive results for tests of cure, which were analyzed separately. Of the remaining 827 samples, 281 (34.0\%) were M. genitalium MRMM-positive by qPCR. The frequency of MRMMs almost doubled from $22.7 \%$ (27/119) in 2014 and $22.3 \%$ (47/211) in 2015 to $44.4 \%$ $(92 / 207)$ in 2016 , then decreased to $39.7 \%(115 / 290)$ in 2017 (Figure 2).

\section{Tests of Cure}

Samples taken from a patient within 6 weeks of an M. genitalium-positive sample were defined as test-of-cure samples. During the study period, we collected 214 samples for test of cure, most $(163 ; 76.2 \%)$ from the second half of 2016 on. Of the 214 samples, 86 (40.2\%) were M. genitalium positive; of these, 67 (77.9\%) were available for further testing. Only $7(10.4 \%)$ samples were found to contain wild-type M. genitalium (Figures 3, 4).

For 57 positive test-of-cure samples, both the initial sample and the test(s)-of-cure samples were available. In

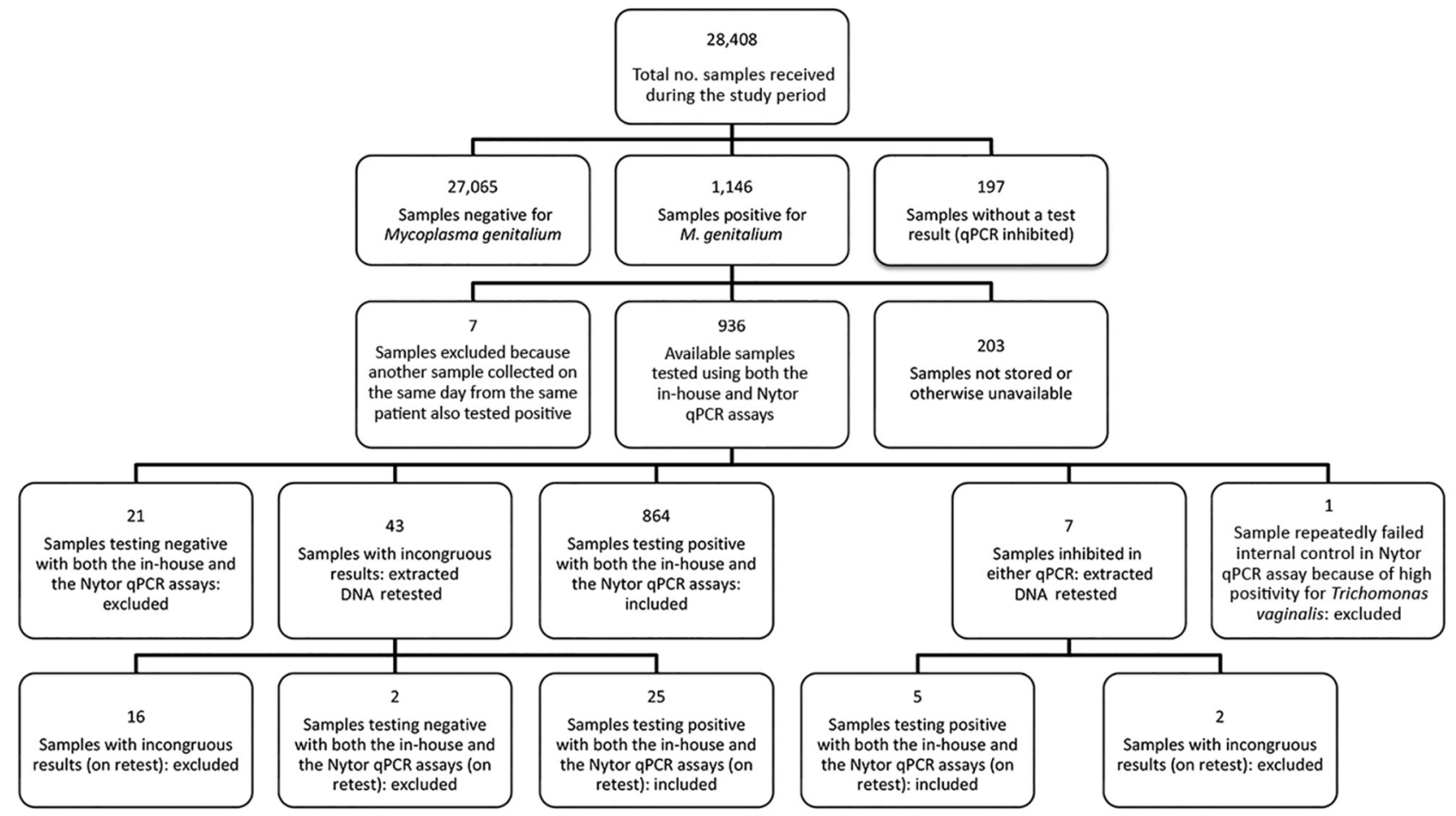

Figure 1. Characteristics of all samples received during study of macrolide-resistant Mycoplasma genitalium in southeastern region of the Netherlands, 2014-2017. qPCR, quantitative PCR. 


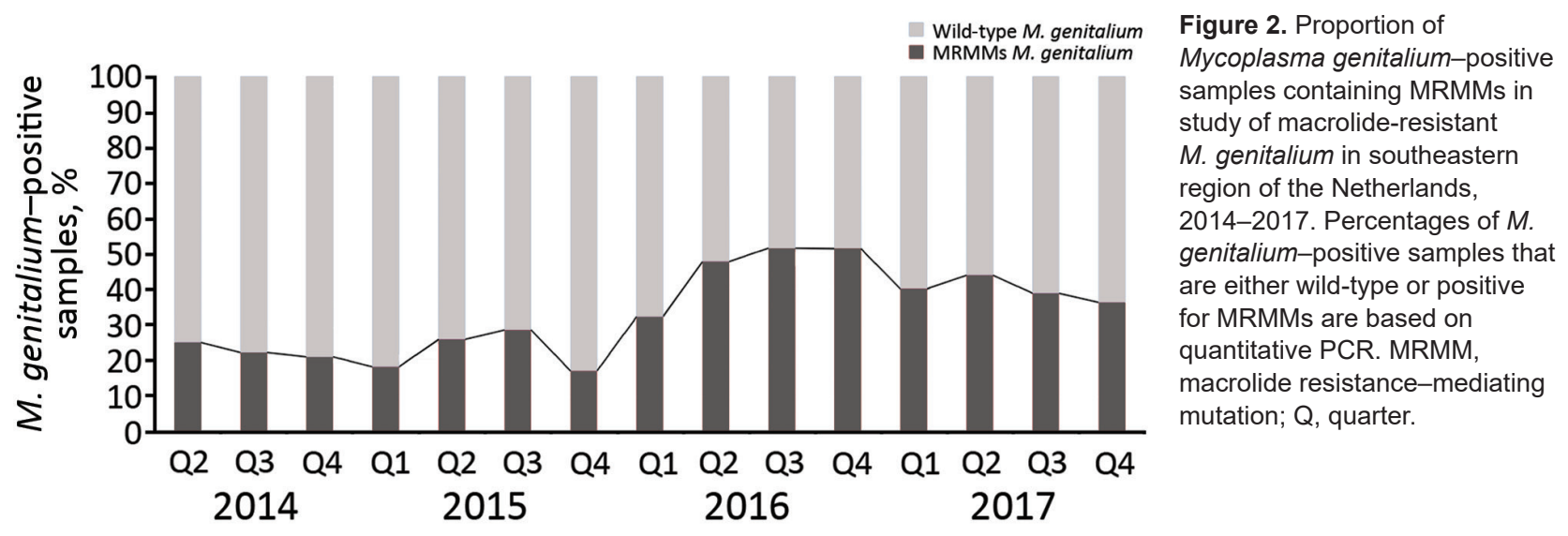

most instances, both samples were positive for MRMMs $(45 / 57 ; 78.9 \%)$.

decreasing number of MRMMs observed in M. genitalium from our study population in 2017 compared with 2016 has not been described before; however, compared with 2014 and 2015, the MRMM prevalence trend is increasing. During the study period, local protocols for the treatment of the aforementioned conditions were unchanged; however, starting on October 3, 2016, the advice to perform a test of cure 3 weeks after treatment was added in print to every report of a positive $M$. genitalium test result. In the preceding months, the advice was often given on an individual basis. Thus, in the second half of 2016, the number of tests of cure increased sharply (Figure 3). This increased testing may help explain the decrease in MRMM frequency because the $40.2 \%$ with a test-of-cure result that was positive for $M$. genitalium would logically have been subsequently treated with a different treatment regimen. However, even in 2017, the year in which most tests of cure were conducted, only about one third of the positive $M$. genitalium samples were followed up by a test of cure. Regardless whether the decreased MRMM frequency resulted from the increased number of tests of cure, the high rate of MRMMs in itself calls for a test of cure after treatment with azithromycin. talium infections, or both $(18,19)$. To our knowledge, the

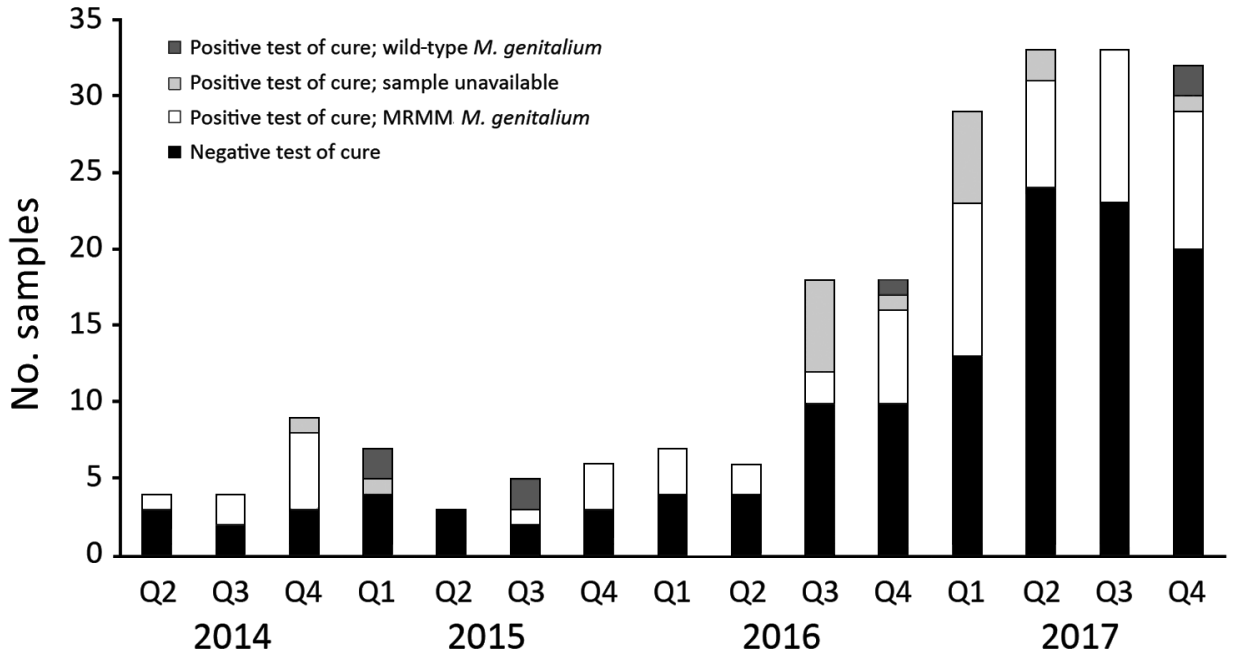

Figure 3. Characteristics of test-of-cure samples in study of macrolide-resistant Mycoplasma genitalium in southeastern region of the Netherlands, 2014-2017. Positive results indicate presence of $M$. genitalium; negative results indicate no $M$. genitalium. Q, quarter. 


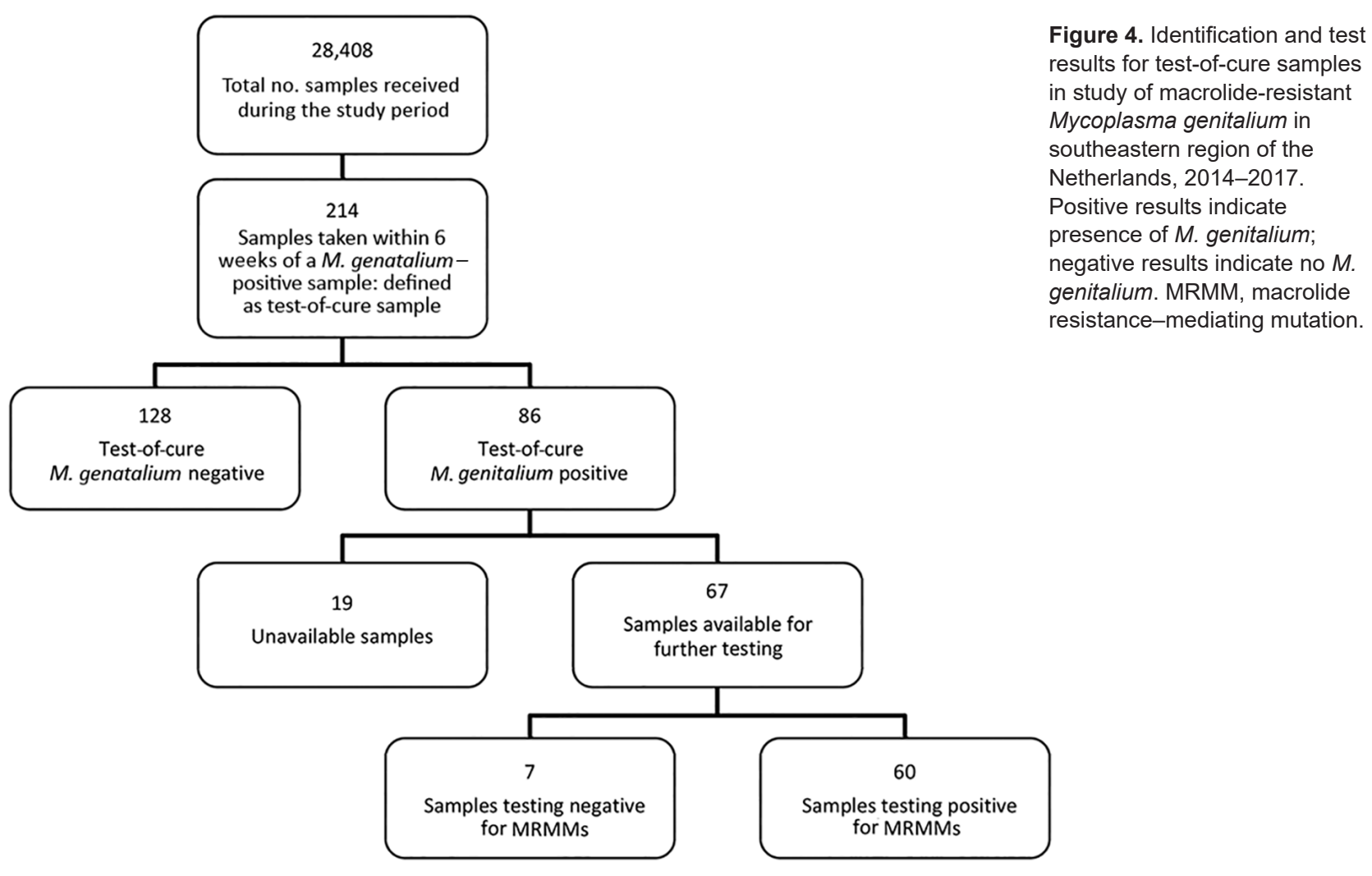

Most positive test-of-cure samples $(60 / 67 ; 89.6 \%)$ contained MRMMs. This finding was expected because given that azithromycin is the preferred treatment for $M$. genitalium according to local protocol, macrolide-susceptible strains would have resulted in a negative test-of-cure result. Of note, for 7 patients who were originally infected with a wild type strain, test-of-cure results indicated a resistant $M$. genitalium strain. One patient with a resistant strain turned out to have a wild-type strain 6 weeks later; however, because it is unknown what treatment these patients received and whether they were at risk of acquiring a second $M$. genitalium infection, we cannot comment on the reason. The 4 patients with a persistent wild-type $M$. genitalium infection may have been reinfected, may have had a resistant $M$. genitalium infection that cannot be detected by the qPCR, may have been prescribed a nonmacrolide drug (e.g., doxycycline), or may have neglected to take the prescribed treatment.

A limitation of our study is the number of samples unavailable for further testing, which was 203 (17.8\%) of 1,139 . The reasons were generally either the sample not being stored or the volume of the stored sample being too low. In the third quarter of 2016, a disproportionately large number of samples $(52 / 83 ; 62.7 \%)$ was lost because of a misunderstanding in storage protocol (i.e., which samples should and should not be stored). Unfortunately, this period coincided with a peak of MRMM frequency $(17 / 31 ; 54.8 \%)$. However, in the fourth quarter of 2016 , only $9 / 81(11.1 \%)$ of samples were lost and MRMM frequency was the same $(38 / 69 ; 55.1 \%)$. Statistically, we found no difference in characteristics of the populations for whom samples were available or unavailable (Table).

The question whether asymptomatic persons should be screened for M. genitalium can only be answered with more research into the clinical aspects and (long-term) complications of (co-)infection with M. genitalium. However, if a single dose of azithromycin indeed predisposes toward the development of MRMMs, $M$. genitalium infection should be excluded before $C$. trachomatis infections are treated with this regimen. In addition, treatment of nongonococcal urethritis should be reevaluated.

In conclusion, high rates (up to 44.4\%) of MRMMs in M. genitalium were found among patients from the southeastern region of the Netherlands who were screened for STDs during 2014-2017. After a sharp initial increase, MRMM prevalence among $M$. genitalium-positive samples declined from the first quarter of $2017 \mathrm{on}$. This finding may or may not be a consequence of the increased number of tests of cure performed during the months immediately preceding the decline. However, regardless of the reason for the decline, we believe that the rates of MRMMs in $M$. genitalium call for a recommendation to perform a test of cure after treatment of $M$. genitalium infections. 


\section{Acknowledgments}

We thank NYtor for providing the necessary number of TVMGres qPCR kits free of charge.

\section{About the Author}

Dr. Martens is a resident physician in clinical microbiology at the Canisius-Wilhelmina Hospital and Radboud University Medical Centre in Nijmegen, the Netherlands. Her research interests include public health and sexual health.

\section{References}

1. Tully JG, Taylor-Robinson D, Cole RM, Rose DL. A newly discovered Mycoplasma in the human urogenital tract. Lancet. 1981;1:1288-91. http://dx.doi.org/10.1016/S0140-6736 (81)92461-2

2. Horner PJ, Gilroy CB, Thomas BJ, Naidoo RO, Taylor-Robinson D. Association of Mycoplasma genitalium with acute non-gonococcal urethritis. Lancet. 1993;342:582-5. http://dx.doi.org/10.1016/ 0140-6736(93)91411-E

3. Jensen JS, Orsum R, Dohn B, Uldum S, Worm AM, Lind K. Mycoplasma genitalium: a cause of male urethritis? Genitourin Med. 1993;69:265-9.

4. Horner PJ, Martin DH. Mycoplasma genitalium infection in men. J Infect Dis. 2017;216(suppl 2):S396-405. http://dx.doi.org/ 10.1093/infdis/jix145

5. Bradshaw CS, Jensen JS, Tabrizi SN, Read TR, Garland SM, Hopkins CA, et al. Azithromycin failure in Mycoplasma genitalium urethritis. Emerg Infect Dis. 2006;12:1149-52. http://dx.doi.org/ 10.3201/eid1207.051558

6. Wiesenfeld HC, Manhart LE. Mycoplasma genitalium in women: current knowledge and research priorities for this recently emerged pathogen. J Infect Dis. 2017;216(suppl 2):S389-95. http://dx.doi.org/10.1093/infdis/jix198

7. Taylor-Robinson D, Jensen JS. Mycoplasma genitalium: from chrysalis to multicolored butterfly. Clin Microbiol Rev. 2011;24:498-514. http://dx.doi.org/10.1128/CMR.00006-11

8. Manhart LE, Jensen JS, Bradshaw CS, Golden MR, Martin DH. Efficacy of antimicrobial therapy for Mycoplasma genitalium infections. Clin Infect Dis. 2015;61(Suppl 8):S802-17. http://dx.doi.org/10.1093/cid/civ785

9. Gambini D, Decleva I, Lupica L, Ghislanzoni M, Cusini M, Alessi E. Mycoplasma genitalium in males with nongonococcal urethritis: prevalence and clinical efficacy of eradication. Sex Transm Dis. 2000;27:226-9. http://dx.doi.org/10.1097/ 00007435-200004000-00008

10. Wikström A, Jensen JS. Mycoplasma genitalium: a common cause of persistent urethritis among men treated with doxycycline. Sex Transm Infect. 2006;82:276-9. http://dx.doi.org/10.1136/ sti.2005.018598

11. Stamm WE, Batteiger BE, McCormack WM, Totten PA, Sternlicht A, Kivel NM; Rifalazil Study Group. A randomized, double-blind study comparing single-dose rifalazil with single-dose azithromycin for the empirical treatment of nongonococcal urethritis in men. Sex Transm Dis. 2007;34:545-52.

12. Manhart LE, Gillespie CW, Lowens MS, Khosropour CM, Colombara DV, Golden MR, et al. Standard treatment regimens for nongonococcal urethritis have similar but declining cure rates: a randomized controlled trial. Clin Infect Dis. 2013;56:934-42. http://dx.doi.org/10.1093/cid/cis1022

13. Anagrius C, Loré B, Jensen JS. Treatment of Mycoplasma genitalium. Observations from a Swedish STD clinic. PLoS One. 2013;8:e61481. http://dx.doi.org/10.1371/journal.pone.0061481
14. Australasian Sexual Health Alliance. Guideline on urethritis [cited 2018 Oct 5]. http://www.sti.guidelines.org.au/syndromes/ urethritis-male\#management

15. De Vries HJC, Van Doornum GJJ. Toelichting bij de nieuwe samenvattingskaart 2014/2015. Diagnostiek en behandeling van seksueel overdraagbare aandoeningen. Tijdschrift voor Infectieziekten. 2014;9:9-11.

16. Centers for Disease Control and Prevention. Sexually transmitted diseases treatment guidelines [cited 2018 Oct 5]. https://www.cdc. gov/std/tg2015/default.htm

17. British Association for Sexual Health and HIV. Guideline on NGU [cited 2018 Oct 1]. https://www.bashh.org/guidelines

18. Jensen JS, Bradshaw CS, Tabrizi SN, Fairley CK, Hamasuna R. Azithromycin treatment failure in Mycoplasma genitalium-positive patients with nongonococcal urethritis is associated with induced macrolide resistance. Clin Infect Dis. 2008;47:1546-53. http://dx.doi.org/10.1086/593188

19. Horner P, Ingle SM, Garrett F, Blee K, Kong F, Muir P, et al. Which azithromycin regimen should be used for treating Mycoplasma genitalium? A meta-analysis. Sex Transm Infect. 2018;94:14-20. http://dx.doi.org/10.1136/sextrans-2016-053060

20. Netherlands Federation of General Physicians. Guideline on sexually transmitted infections [in Dutch] [cited 2018 Oct 5]. https://www. nhg.org/standaarden/volledig/nhg-standaard-het-soa-consult

21. National Institute for Public Health and the Environment. Guideline on sexually transmitted infections in government-funded STI-clinics [in Dutch] [cited 2018 Oct 5]. https://lci.rivm.nl/ draaiboeken/consult-seksuele-gezondheid

22. Netherlands Association of Dermatology and Venereology. Multidisciplinary guideline on diagnostics and treatment of sexually transmitted infections [in Dutch] [cited 2018 Oct 5]. http://www.nvdv.nl/wp-content/uploads/2014/08/Definitievemultidisciplinaire-richtlijn-soa-herziening-2018.pdf

23. Jensen JS, Björnelius E, Dohn B, Lidbrink P. Use of TaqMan 5' nuclease real-time PCR for quantitative detection of Mycoplasma genitalium DNA in males with and without urethritis who were attendees at a sexually transmitted disease clinic. J Clin Microbiol. 2004;42:683-92. http://dx.doi.org/10.1128/ JCM.42.2.683-692.2004

24. Twin J, Jensen JS, Bradshaw CS, Garland SM, Fairley CK, Min LY, et al. Transmission and selection of macrolide resistant Mycoplasma genitalium infections detected by rapid high resolution melt analysis. PLoS One. 2012;7:e35593. http://dx.doi.org/10.1371/journal.pone.0035593

25. Anderson T, Coughlan E, Werno A. Mycoplasma genitalium macrolide and fluoroquinolone resistance detection and clinical implications in a selected cohort in New Zealand. J Clin Microbiol. 2017;55:3242-8. http://dx.doi.org/10.1128/JCM.01087-17

26. Barberá MJ, Fernández-Huerta M, Jensen JS, Caballero E, Andreu A. Mycoplasma genitalium macrolide and fluoroquinolone resistance: prevalence and risk factors among a 2013-2014 cohort of patients in Barcelona, Spain. Sex Transm Dis. 2017;44:457-62. http://dx.doi.org/10.1097/OLQ.0000000000000631

27. Braam JF, Slotboom B, Van Marm S, Severs TT, Van Maarseveen NM, Van Zwet T, et al. High prevalence of the A2058T macrolide resistance-associated mutation in Mycoplasma genitalium strains from the Netherlands. J Antimicrob Chemother. 2017;72:1529-30. http://dx.doi.org/10.1093/jac/dkw584

28. Couldwell DL, Jalocon D, Power M, Jeoffreys NJ, Chen SCA, Lewis DA. Mycoplasma genitalium: high prevalence of resistance to macrolides and frequent anorectal infection in men who have sex with men in western Sydney. Sex Transm Infect. 2018;94:406-10. http://dx.doi.org/10.1136/sextrans-2017-053480

29. Gossé M, Lysvand H, Pukstad B, Nordbø SA. A novel SimpleProbe PCR assay for detection of mutations in the $23 \mathrm{~S}$ rRNA gene associated with macrolide resistance in Mycoplasma 
genitalium in clinical samples. J Clin Microbiol. 2016;54:2563-7. http://dx.doi.org/10.1128/JCM.01233-16

30. Gratrix J, Plitt S, Turnbull L, Smyczek P, Brandley J, Scarrott R, et al. Prevalence and antibiotic resistance of Mycoplasma genitalium among STI clinic attendees in western Canada: a cross-sectional analysis. BMJ Open. 2017;7:e016300. http://dx.doi.org/10.1136/bmjopen-2017-016300

31. Nijhuis RH, Severs TT, Van der Vegt DS, Van Zwet AA, Kusters JG. High levels of macrolide resistance-associated mutations in Mycoplasma genitalium warrant antibiotic susceptibility-guided treatment. J Antimicrob Chemother. 2015; 70:2515-8. http://dx.doi.org/10.1093/jac/dkv136

32. Read TRH, Fairley CK, Tabrizi SN, Bissessor M, Vodstrcil L, Chow EPF, et al. Azithromycin $1.5 \mathrm{~g}$ over 5 days compared to $1 \mathrm{~g}$ single dose in urethral Mycoplasma genitalium: impact on treatment outcome and resistance. Clin Infect Dis. 2017;64:250-6. http://dx.doi.org/10.1093/cid/ciw719

33. Salado-Rasmussen K, Jensen JS. Mycoplasma genitalium testing pattern and macrolide resistance: a Danish nationwide retrospective survey. Clin Infect Dis. 2014;59:24-30. http://dx.doi.org/10.1093/ $\mathrm{cid} / \mathrm{ciu} 217$
34. Tabrizi SN, Su J, Bradshaw CS, Fairley CK, Walker S, Tan LY, et al. Prospective evaluation of ResistancePlus MG, a new multiplex quantitative PCR assay for detection of Mycoplasma genitalium and macrolide resistance. J Clin Microbiol. 2017; 55:1915-9. http://dx.doi.org/10.1128/ JCM.02312-16

35. Tagg KA, Jeoffreys NJ, Couldwell DL, Donald JA, Gilbert GL. Fluoroquinolone and macrolide resistanceassociated mutations in Mycoplasma genitalium. J Clin Microbiol. 2013;51:2245-9. http://dx.doi.org/10.1128/ JCM.00495-13

36. Trembizki E, Buckley C, Bletchly C, Nimmo GR, Whiley DM High levels of macrolide-resistant Mycoplasma genitalium in Queensland, Australia. J Med Microbiol. 2017;66:1451-3. http://dx.doi.org/10.1099/jmm.0.000584

Address for correspondence: Ferry Hagen, Canisius-Wilhelmina Hospital, Department of Medical Microbiology and Infectious Diseases, Weg door Jonkerbos 100, NL-6532SZ Nijmegen, the Netherlands; email: f.hagen@gmail.com

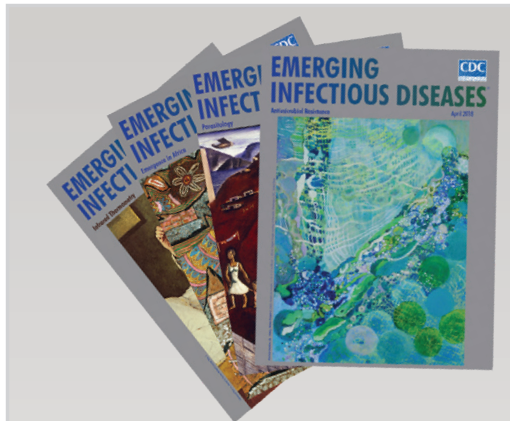

- Seroprevalence of Chikungunya Virus in 2 Urban Areas of Brazil 1 Year after Emergence

- Two Infants with Presumed Congenital Zika Syndrome, Brownsville, Texas, USA, 2016-2017

- Reemergence of Intravenous Drug Use as Risk Factor for Candidemia, Massachusetts, USA

- Rickettsial Illnesses as Important Causes of Febrile Illness in Chittagong, Bangladesh

- Influence of Population Immunosuppression and Past Vaccination on Smallpox Reemergence

- Emerging Coxsackievirus A6 Causing Hand, Foot and Mouth Disease, Vietnam

- Influenza A(H7N9) Virus Antibody Responses in Survivors 1 Year after Infection, China, 2017

- Genomic Surveillance of 4CMenB Vaccine Antigenic Variants among Disease-Causing Neisseria meningitidis Isolates, United Kingdom, 2010-2016

- Evolution of Sequence Type 4821 Clonal Complex Meningococcal Strains in China from Prequinolone to Quinolone Era, 1972-2013

- Avirulent Bacillus anthracis Strain with Molecular Assay Targets as Surrogate for Irradiation-Inactivated Virulent Spores

\section{Antimicrobial Resistance}

- Phenotypic and Genotypic Characterization of Enterobacteriaceae Producing Oxacillinase-48-Like Carbapenemases, United States

- Bacterial Infections in Neonates, Madagascar, 2012-2014

- Artemisinin-Resistant Plasmodium falciparum with High Survival Rates, Uganda, 2014-2016

- Carbapenem-Nonsusceptible Acinetobacter baumannii, 8 US Metropolitan Areas, 2012-2015

- Cooperative Recognition of Internationally Disseminated Ceftriaxone-Resistant Neisseria gonorrhoeae Strain

- Imipenem Resistance in Clostridium difficile Ribotype 017, Portugal

- Enhanced Replication of Highly Pathogenic Influenza A(H7N9) Virus in Humans

- Multidrug-Resistant Salmonella enterica 4,[5],12:i:-Sequence Type 34, New South Wales, Australia, 2016-2017

- Genetic Characterization of Enterovirus A71 Circulating in Africa

- Emergomyces canadensis, a Dimorphic Fungus Causing Fatal Systemic Human Disease in North America

- mcr-1 in Carbapenemase-Producing Klebsiella pneumoniae in Hospitalized Patients, Portugal, 2016-2017 